\title{
Chronic energy deficiency and associated factors among adults living with HIV in Gondar University Referral Hospital northwest Ethiopia
}

Melkitu Fentie ${ }^{1 *}$, Molla Mesele Wassie ${ }^{1}$, Adino Tesfahun², Kassahun Alemu², Malede Mequanent ${ }^{2}$ and Tadesse Awoke Ayele ${ }^{2}$

\begin{abstract}
Background: Human Immunodeficiency Virus (HIV) infection and chronic energy deficiency are bidirectional and multifaceted. HIV can cause or worsen chronic energy deficiency by increasing energy requirements, reducing food intake and nutrient absorption. Chronic energy deficiency weakens the immune system, increase the susceptibility to infections and worsening the disease impact. Studies on the magnitude and factors associated with chronic energy deficiency among adults living with HIV are limited. The aim of this study was to assess the prevalence of chronic energy deficiency and associated factors among adults living with HIV in Gondar University Referral Hospital, northwest Ethiopia.

Methods: An institution based cross-sectional study was conducted and systematic random sampling was used to select study subjects. A total of 317 study subjects were enrolled in the study. Structured and pretested questionnaire was used to collect socio-demographic, economic and diet related variables. Weight and height measurement were taken and medical charts were reviewed. Laboratory analysis for CD4 count and anemia was done. Bi-variable and multi-variable logistic regression analyses were used to assess the effect of different factors on chronic energy deficiency.

Results: A total of 317 patients provide complete information with response rate of $99.4 \%$. The overall prevalence of chronic energy deficiency was $18.3 \%$ (95\%Cl: $14.5 \%-22.7 \%)$. The prevalence of mild, moderate and severe chronic energy deficiency was 11.4, 3.5 and 3.5\% respectively. No formal education ( $\mathrm{OOR}=2.05,95 \% \mathrm{Cl}: 1.01,4.21$ ), being in the WHO clinical stage three and four $(\mathrm{AOR}=3.84,95 \% \mathrm{Cl}: 1.39,10.61)$ and history of diarrhea in the last two weeks prior to the survey ( $A O R=4.43,95 \% \mathrm{Cl}: 1.83,10.72$ ) were significantly associated with chronic energy deficiency.

Conclusion: The prevalence of chronic energy deficiency among adults living with HIV was medium public health problem. Educational status, WHO clinical stage, and history of diarrhea in the last two weeks prior to the survey were risks for chronic energy deficiency. Integration of nutritional management with HAART, early diagnosis and treatment of diarrheal disease would be supreme important.
\end{abstract}

Keywords: Chronic energy deficiency, Malnutrition, HIV, Gondar

\footnotetext{
* Correspondence: melkitu12@gmail.com

'Department of Human Nutrition, College of Medicine and Health Sciences,

University of Gondar, Gondar, Ethiopia

Full list of author information is available at the end of the article
} 


\section{Background}

Globally, 36.7 million people were living with Human Immunodeficiency Virus (HIV) and an estimated $0.8 \%$ of adults were affected at the end of 2015 [1]. Although the burden of the epidemic varies between countries and regions, Sub-Saharan Africa (SSA) is the region most affected and it is a home for nearly $70 \%$ of the world people living with HIV (PLWH) with an adult prevalence rate of $4.4 \%$. Moreover, HIV is the leading cause of adult morbidity and mortality in this region $[1,2]$. Ethiopia is one of the seriously affected countries in SSA with a large number of $(769,600)$ PLWH and 15,700 new infections annually. According to 2014 estimate, the national HIV prevalence rate was 1.14\% [3].

The relationship between HIV and chronic energy deficiency (CED) represents a classic example of well recognized vicious cycle of immune dysfunction, infectious disease, and malnutrition. Any immune impairment as a result of $\mathrm{HIV}$ can contribute to CED. In turn CED leads to immune impairment, worsens the effects of HIV, and contributes to a more rapid progression of the disease [4]. An HIV-infected person is more at risk for CED due to reduced food intake, poor absorption, and change in metabolism, by chronic infections and other illnesses [5]. Poor nutritional status is one of the major complications of HIV and a significant factor to have full-blown AIDS. Individuals who are severely chronic energy deficient have a six times higher risk of dying in the first 3 months of starting ART than those with a normal nutritional status $[6,7]$. In most developing countries chronic energy deficiency with other infectious disease aggravated the HIV pandemic and contributed for morbidity and mortality of patients $[5,8,9]$.

Even though there is a major advance in antiretroviral treatment and survival outcomes, Chronic Energy Deficiency (CED) remain a significant public health concern among HIV infected groups [10]. More than 800 million people worldwide are chronically undernourished from which 200 million are living in SSA, and greater than 33 million are living with HIV infection [11]. CED, the most common form of adult malnutrition in the SSA, is associated with significant morbidity and compounds the immunosuppressive effects of HIV [12]. A reported by a meta-analysis conducted in Sub-Saharan countries the pooled prevalence of HIV related CED was $10.3 \%$ and the prevalence in Ethiopian was $13.2 \%$ [13]. According to the Studies done in Brazil and India the prevalence of chronic energy deficiency among HIV infected individuals was 43 and $28.56 \%$ respectively $[14,15]$. Moreover in Botswana, Tanzania and Nigeria, it was $28.5,18.4$ and $5.8 \%$ respectively [16-18]. In Ethiopia, Addis Ababa city, it was $18 \%$ [19] and in Butajira Hospital the overall prevalence of CED was $25.2 \%$ and of which 49,19 , and $9 \%$ patients had mild, moderate, and severe CED respectively [20].
Age, anemia, CD4 count below two hundred and being widowed were the determinant factors of chronic energy deficiency among adults living with HIV in Dembia district [21].

Though many advances in the fight against HIV have been made in Ethiopia, sufficient effort has not been put into promoting adequate nutrition for PLHIV.As a result the Federal Minister of Health (FMOH) of Ethiopia has launched the National Nutrition Program (NNP) to address nutrition problems in a comprehensive manner by including nutrition and HIV/AIDS as part of its complete service delivery. There is also a Guideline named' National Guidelines for HIV/AIDS and Nutrition' to provide a standardized nutrition care and support for PLHIV in diverse conditions [22].

Even though there was a previous study in the study area, it was done before the implementation of nutrition assessment, counseling and support program in the Hospital. Therefore, the aim of this study was to determine the prevalence and factors associated with chronic energy deficiency among adults living with HIV in Gondar University Referral Hospital, North West Ethiopia, Gondar.

\section{Methods}

\section{Study area and period}

The study was conducted at Gondar University Referral Hospital HIV care clinic from March to April; 2016. Gondar University Referral Hospital HIV care clinic is located in North Gondar administrative zone, Amhara National Regional state, which is about $727 \mathrm{~km}$ northwest of Addis Ababa, the capital city of Ethiopia. The hospital serves about five million people of the northwest Ethiopia. The HIV care service of the hospital was initiated in 2005 and has 7 outpatient rooms, one voluntary testing and counseling room, one pharmacy, and laboratory rooms. It has three adult ART clinic, one pediatric, one VCT and 2 adherence counseling clinic. Daily about 30-40 HIV positive clients visit the clinic. Since 2005, 7581 adults have enrolled in the clinic. Currently, about 4891 adults are actively following their treatment.

\section{Source and study population}

All HIV positive adults ( $\geq 18$ years) who were enrolled for chronic HIV care at Gondar University referral Hospital ART clinic were the source population and those adults living with HIV/AIDS who came to Gondar University Referral Hospital for a follow up during the study period were our study population.

\section{Inclusion and exclusion criteria}

Adults age 18 and above living with HIV who visited the ART clinic during the study period were included in the 
study while pregnant women and adult with spinal problem (kyphosis) were excluded from the study.

\section{Sample size determination and sampling procedure}

The required sample size was calculated using single population formula $n=\left(\left(z \frac{\alpha}{2}\right)^{2} * p(1-p)\right) / w 2 \quad$ [23], where $\mathbf{n}$ is the sample size, $\mathbf{z}$ is the value of standard normal distribution corresponding to a significant level of $\alpha$ of 0.005 which is $1.96, \mathrm{w}$ is the margin of error which was taken as $5 \%$ and $\mathbf{p}$ is the estimated proportion of the target population by taking the prevalence of chronic energy deficiency as $25.2 \%$ [20] and adding $10 \%$ non- response error the final sample size computed was 319. In order to get sampling interval (k), the total population was divided by the sample size required. The data collection was planned to be finished within one month having 22 working days. To select our study participants, we considered the working days and the average daily patient flow in the ART clinic. The average daily patient flow was 30-40 (we took 35). The total expected number of patients to attend the clinic during the data collection period was 770 and to select 319 of our study participants, we used a systematic random sampling with a sampling interval of $770 / 319 \approx 2$. The first participant was selected using random starting point of lottery method. Subjects were chosen at regular intervals by adding two from each prior participant at their exit from the ART clinic.

\section{Data collection tool and procedures}

An interviewer administered pretested structured questioner was used to collect the socio demographic characteristics like sex, age, residence, marital status, educational level and occupation of study participants. Similarly, The household economic status of the participants was assessed by house hold wealth index questions which were extracted from EDHS 2011 [24]. It was assessed by using the selected household assets, house ownership, main materials of the roof and floor, toilet facility, source of drinking water and fuel, size of agricultural land, livestock ownership, microfinance bank account and receiving cash or food from safety net program. First variables were coded between 0 and 1 . Then, principal component analysis was carried out. In the principal component analysis, the power of the variables to explain wealth status was determined step by step using the communalities values. Those variables having communality value of greater than 0.5 were used to produce factor scores. Hence, an Eigen value of greater than one was considered. Finally this factor scores were summed and ranked in to tertile as low, medium and high [25].

Tools for measuring the dietary diversity was adopted from FAO guidelines for measuring house hold and individual dietary diversity. Dietary Diversity Score (DDS) was assessed by asking the respondents to list all the food items they consumed in the last $24 \mathrm{~h}$ preceding the survey day. We used food groups in local context. Then the reported food items were classified into nine food groups. Respondents with dietary diversity score three and below were classified as having inadequate dietary diversity score while respondents with dietary diversity score above three were taken as having adequate dietary diversity score [26].

Anthropometric measurement (height and weight) was done to have information on the individuals' Body mass index (BMI). Weight of the study participants was measured to the nearest $0.1 \mathrm{Kg}$ of a standing beam balance. It was measured with lightly clothing and no shoes. Calibration was done before weighing each participant by setting it to zero. Weighing scale also checked against a standard weight for its accuracy on daily basis. Height of the participant was measured using 'Seca' vertical height measuring scale standing upright in the middle of board. It was measured following standard procedures. Participants' takeoff their shoes, stand erect and look straight in horizontal plain. The occiput, shoulder, buttocks, and heels touched measuring board [27, 28] and it was recorded to the nearest $0.5 \mathrm{~cm}$.. BMI was calculated as weight in kilograms divided by the square of height in meters $\left(\mathrm{kg} / \mathrm{m}^{2}\right)$. BMI was classified according to WHO classification [29]. Less than $18.50 \mathrm{~kg} / \mathrm{m}^{2}$ taken as chronic energy deficiency (CED) and it was further classified as Mild CED if BMI was $17.00-18.49 \mathrm{~kg} / \mathrm{m}^{2}$, Moderate $16.00-16.99 \mathrm{~kg} / \mathrm{m}^{2}$ and severe less than $16.00 \mathrm{~kg} / \mathrm{m}^{2}$. Patients who was considered as not having CED were normal (BMI 18.5-24.49 $\mathrm{kg} / \mathrm{m}^{2}$ ), overweight $\left(24.5-30.0 \mathrm{~kg} / \mathrm{m}^{2}\right)$ and obese $\left(>30 \mathrm{~kg} / \mathrm{m}^{2}\right)$.

Stage of the disease, ART status and drug regimen were accessed on the patients' medical chart. Blood sample was drawn from subjects as part of routine monthly ART follow up investigation to measure CD4 cell count and Hemoglobin level.

\section{Laboratory}

Hemoglobin was measured with Cell Dyne hematology analyzer (US). Hemoglobin level $<13 \mathrm{~g} / \mathrm{dl}$ for men and < $12.0 \mathrm{~g} / \mathrm{dl}$ for women patients was considered as anemic [30].CD4 + T cell count was measured with BD FACS machine (US) and categorized according to different literatures by taking 200 as a cutoff point [31].

\section{Data processing and analysis}

Data were checked for completeness, entered and coded using EPI-INFO version 7 software. Analysis was carried out using Statistical Package for Social Science (SPSS) version 20 statistical program. Frequencies and graphs were used to explore the data. Binary logistic regression 
analysis was used to identify the confounders. Variables with a $p$-value of $<0.2$ and variables which were highly significant in other studies were entered to multi-variable logistic regression (Back ward likelihood ratio variable selection method) to identify factors which have statistically significant association. Adjusted odds ratio (AOR) with 95\% confidence interval and $p$-value $<0.05$ was used to show association between explanatory variables and dependent variable. The fit of the model was assessed using the Hosmer-Lemeshow goodness-of-fit test and $p$-value > 0.05 was taken as a cutoff point.

\section{Result}

A total of 317 adults living with HIV who were in pre and on ART care were included in the study with a response rate of $99.4 \%$. Two hundred five $(64.7 \%)$ of the participants were females and regarding the participants marital status, about half (50.2\%) were currently married. The age of the respondent's ranges from 18 to 70 and the mean age of the respondents was 38.5 years with a standard deviation $(\mathrm{SD}) \pm 9.86$. One hundred and seventy $(53.6 \%)$ of study participants were in the age range of 30-44 years old. Ninety (28.4\%) were jobless while farmers accounted for $5.4 \%$ of cases. Of 317 participants, $287(90.5 \%)$ were urban residents. About one third (30.6\%) of the study participants had no formal education, while $38.8 \%$ had secondary education and above. Regarding the house hold wealth index, about one third had low wealth status (Table 1).

\section{Clinical profile and anti-retroviral therapy status}

The clinical status of participants showed that 267(84.2\%) were at WHO stage one. Two hundred seventy five (86.8\%) were on ART of which Ninety $(36 \%)$ were on AZT-3TC-NVP and another eighty seven (31.6\%) were on TDF-3TC-EFV Regimen. The median CD4+ T-cell count of participants were 400 cells/ $\mu$ l with Inter -quartile range (IQR: 266.5, 593.5).In addition, 25(7.9\%) had history of diarrhea in the past two weeks prior to the survey (Table 2).

\section{Nutritional status}

The overall prevalence of chronic energy deficiency (BMI $<18.5 \mathrm{~kg} / \mathrm{m}^{2}$ ) among adults living with HIV was $18.3 \%$ (95\%CI: 14.5\%-22.7\%). Mild, Moderate and Severe chronic energy deficiency was observed on 36(11.4\%), 11 (3.5\%) and 11(3.5\%) participants respectively. The mean BMI was $21.5 \pm 3.6 \mathrm{Kg} / \mathrm{m}^{2}$. Of 317 study participants, $278(87.7 \%)$ had inadequate dietary diversity, of which 41(81\%) were having chronic energy deficiency (Fig. 1).

The prevalence of chronic energy deficiency among female participants was $19 \%$. Among all patients who had chronic energy deficiency, the proportion of CED
Table 1 Socio-demographic characteristics of adults living with HIV at Gondar University Referral Hospital, Gondar; May $2016(n=317)$

\begin{tabular}{|c|c|c|c|}
\hline Variable & & Frequency & Percent (\%) \\
\hline \multirow[t]{2}{*}{ Sex } & Female & 205 & 64.7 \\
\hline & Male & 112 & 35.3 \\
\hline \multirow[t]{3}{*}{ Age in years } & $18-29$ & 54 & 17 \\
\hline & $30-44$ & 170 & 53.6 \\
\hline & $>45$ & 93 & 29.3 \\
\hline \multirow[t]{2}{*}{ Residence } & Urban & 287 & 90.5 \\
\hline & Rural & 30 & 9.5 \\
\hline \multirow[t]{2}{*}{ Marital Status } & Currently unmarried & 158 & 49.8 \\
\hline & Currently married & 159 & 50.2 \\
\hline \multirow[t]{2}{*}{ Religion } & Orthodox & 295 & 93.1 \\
\hline & Muslim & 22 & 6.9 \\
\hline \multirow[t]{2}{*}{ Ethnicity } & Amhara & 288 & 90.9 \\
\hline & Others & 29 & 9.1 \\
\hline \multirow[t]{2}{*}{ Occupation } & Unemployed & 90 & 28.4 \\
\hline & Employed & 227 & 71.6 \\
\hline \multirow[t]{3}{*}{ Educational status } & No formal education & 97 & 30.6 \\
\hline & Primary & 97 & 30.6 \\
\hline & Secondary and above & 123 & 38.8 \\
\hline \multirow[t]{3}{*}{ Wealth Index } & Low & 105 & 33.1 \\
\hline & Medium & 106 & 33.4 \\
\hline & High & 106 & 33.4 \\
\hline
\end{tabular}

was high in age group between 30 and 44 which was 30 (51.7\%) followed by age group 18-29 and $\geq 45$ each accounted $14(24.1 \%)$. Considering the participants residence, $48(82.8 \%)$ of chronic energy deficient participants were urban dwellers (Table 3).

Fourteen $(24.1 \%)$ of participants who were on preART and $44(75.9 \%)$ who were on ART had chronic energy deficiency. Of the 58 chronic energy deficient individuals $10(17.2 \%)$ were having CD4 count less than two hundred.

The overall prevalence of anemia was $25.1 \%$ and among chronic energy deficient individuals $34.5 \%$ were anemic.

\section{Associated factors of chronic energy deficiency}

The covariates, residence, educational status, ART status, stage of the disease, toilet availability and diarrhea were significantly associated with chronic energy deficiency in the bi-variable analysis. In the adjusted analysis, educational status, stage of the disease and having diarrhea in the past two weeks prior to the survey were significantly associated with chronic energy deficiency. The risk of developing chronic energy deficiency of no formal education increased risk of by $2(\mathrm{AOR}=2.05,95 \% \mathrm{CI}: 1.005,4.210)$ as 
Table 2 Clinical Profile and ART status of adults living with HIV in GURH, 2016 $(n=317)$

\begin{tabular}{|c|c|c|}
\hline Variable & Frequency & Percent (\%) \\
\hline \multicolumn{3}{|l|}{ Stage of the disease } \\
\hline One & 267 & 84.2 \\
\hline Two & 31 & 9.8 \\
\hline Three and above & 19 & 6 \\
\hline \multicolumn{3}{|l|}{ ART status } \\
\hline Pre-ART & 42 & 13.2 \\
\hline On ART & 275 & 86.6 \\
\hline \multicolumn{3}{|l|}{ Regimen } \\
\hline AZT-3TC-NVP & 99 & 36 \\
\hline AZT-3TC-EFV & 40 & 14.5 \\
\hline TDF-3TC-EFV & 87 & 31.6 \\
\hline TDF-3TC-NVP & 36 & 13.1 \\
\hline Second line & 13 & 4.1 \\
\hline \multicolumn{3}{|l|}{ CD4 count } \\
\hline$<200$ cells $/ \mu \mathrm{L}$ & 130 & 41 \\
\hline$\geq 200$ cells $/ \mu \mathrm{L}$ & 187 & 59 \\
\hline \multicolumn{3}{|l|}{ Hemoglobin } \\
\hline Normal & 236 & 74.9 \\
\hline Anemic & 79 & 25.1 \\
\hline \multicolumn{3}{|l|}{ Diarrhea } \\
\hline Yes & 25 & 7.9 \\
\hline No & 292 & 92.1 \\
\hline
\end{tabular}

compared to those having secondary education and above. With regard to the clinical stage of the disease, those who are in the WHO stage three and four were 3.84 times $(\mathrm{AOR}=3.84,95 \% \mathrm{CI}: 1.83,10.72)$ at risk of having chronic energy deficiency than those in stage one. Those who had history of diarrhea in the last two weeks prior to the survey were 4.43 times $(\mathrm{AOR}=4.43,95 \% \mathrm{CI}: 1.83,10.72)$ at

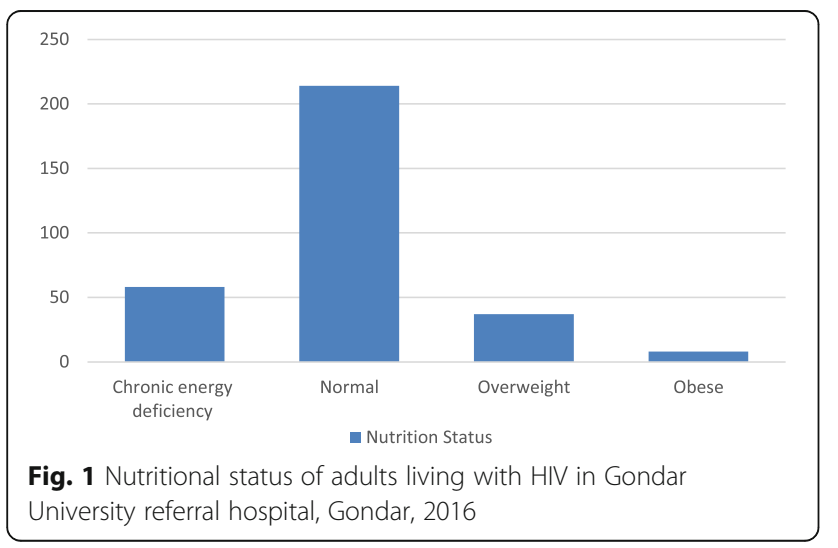

risk of having chronic energy deficiency than their counter parts (Table 4).

\section{Discussion}

Recognizing the magnitude of malnutrition in PLWH is important because it may predict disease progression and higher risk of morbidity and mortality. The presence of chronic energy deficiency is a predictor of worse outcome in HIV infected individuals [32]. This study aimed on assessing the prevalence of chronic energy deficiency and its associated factors among PLWH. In this study the overall prevalence of chronic energy deficiency was $18.3 \%$ and according to Nutrition Landscape Information System (NLIS) cutoff values, the burden of CEM was founds to be in medium public health significance [33]. Educational status, WHO clinical stage and having diarrhea in the last two weeks were significantly associated with chronic energy deficiency.

The overall prevalence of chronic energy deficiency in this study was similar with the studies done in Nepal and Singapore [34, 35], Tanzania [17] and Ethiopian studies done in Butajira, Dilla, Addis Abeba and Dembia [19-21, 36]. But it was lower than the findings from Iran, China, Brazil, Botswana, Bahirdar, Humera and Gondar $[14,18,31,37-40]$. Higher prevalence of chronic energy deficiency was also observed in this study as compared to a study conducted in Nigeria [16]. The discrepancy in the prevalence of chronic energy deficiency among different countries might be due to the difference in sociocultural and economic characteristics, diet diversity, and year of the study. Especially the studies done in Bahirdar and Gondar which has a similar setting with the current study might be explained by the time variation between the studies and the improved nutrition assessment and counseling services in the country. High prevalence of CED in Humera is due to the study conducted among women living with HIV whom are biologically, socially and economically vulnerable groups and this will add fuel to their nutritional status. In addition, studies in Brazil and China were conducted among hospitalized patients among whom the probability of the presence of different opportunistic infections is increased which further predisposes to CED.

This study revealed that, being in WHO stage three and four had 3.84 times risk for chronic energy deficiency. Studies from Nepal $(\mathrm{AOR}=2.09)$, Hosanna $(\mathrm{AOR}=5.23)$ and Dilla $(\mathrm{AOR}=12.9)$ also showed similar findings $[34,36,41]$. When the disease stage advances over time, the occurrence of CED is inevitable due to the occurrence and synergetic effect of different opportunity infections which increases their 
Table 3 nutritional status and socio-demographic characteristics, ART status and Dietary diversity of adults living with HIV in GURH, 2016

\begin{tabular}{|c|c|c|c|c|}
\hline \multirow[t]{2}{*}{ Variable } & & \multicolumn{2}{|c|}{ Chronic-energy deficiency } & \multirow{2}{*}{$\begin{array}{l}\text { total } \\
\text { Number } \%\end{array}$} \\
\hline & & Yes Number (\%) & No Number (\%) & \\
\hline \multirow[t]{2}{*}{ Sex } & Female & $39(19 \%)$ & $166(81 \%)$ & $205(100 \%)$ \\
\hline & Male & 19(17\%) & $93(83 \%)$ & $112(100 \%)$ \\
\hline \multirow[t]{3}{*}{ Age in year } & $18-29$ & $14(26 \%)$ & $40(74 \%)$ & $54(100 \%)$ \\
\hline & $30-44$ & $30(17.6 \%)$ & $140(82.3 \%)$ & $170(100 \%)$ \\
\hline & $\geq 45$ & $14(15 \%)$ & 79(85\%) & $93(100 \%)$ \\
\hline \multirow[t]{2}{*}{ Marital status } & Currently unmarried & $34(21.5 \%)$ & $124(78.4 \%)$ & 158(100\%) \\
\hline & Currently married & $24(15 \%)$ & 135(85\%) & 159(100\%) \\
\hline \multirow[t]{3}{*}{ Educational status } & No formal education & $27(27.8 \%)$ & $70(72.1 \%)$ & $97(100 \%))$ \\
\hline & Primary & $15(15.4 \%)$ & $82(84.5 \%)$ & $97(100 \%)$ \\
\hline & Secondary and above & $16(13 \%)$ & 107(87\%) & $123(100 \%)$ \\
\hline \multirow[t]{2}{*}{ Residence } & Urban & $48(16.7 \%)$ & 239(83.2\%) & $287(100 \%)$ \\
\hline & Rural & 10(33\%) & $20(67 \%)$ & $30(100 \%)$ \\
\hline \multirow[t]{2}{*}{ Ethnicity } & Amhara & $53(18.4 \%)$ & $235(81.5 \%)$ & $288(100 \%)$ \\
\hline & Others & $5(17.2 \%)$ & $24(82.7 \%)$ & $29(100 \%)$ \\
\hline \multirow[t]{3}{*}{ Wealth Index } & Low & $26(24.7 \%)$ & $79(75.2 \%)$ & $105(100 \%)$ \\
\hline & Medium & $14(13.2 \%)$ & $92(86.7 \%)$ & 106(100\%) \\
\hline & High & 18(17\%) & $88(83 \%)$ & $106(100 \%)$ \\
\hline \multirow[t]{2}{*}{ Dietary diversity } & Inadequate & $47(17 \%)$ & $231(83 \%)$ & 278(100\%) \\
\hline & Adequate & $11(39.2 \%)$ & $28(60.7 \%)$ & 39(100\%) \\
\hline \multirow[t]{2}{*}{ ART status } & Pre-ART & 14(33.3) & $28(66.7 \%)$ & $42(100 \%)$ \\
\hline & On ART & $44(16 \%)$ & $231(84 \%)$ & $275(100 \%)$ \\
\hline
\end{tabular}

catabolic state, energy demand and loss of both macro and micronutrients by decreasing the intake and absorption of nutrients. In addition, when the disease stage advances fatigue increases and it decreases their physical activity and then work productivity which compromise their house hold income, food purchasing power and diminish their probability to get nutritious and adequate food further affect their nutritional status $[5,42]$.

Poor nutrition is associated with prolonged diarrhea. Each day of illness due to diarrhea produces a weight loss of 20-40 g [43]. Diarrhea increases caloric needs by $25 \%$ and often leads to a decreased oral intake, Increased loss of and decreased absorption of vitamin, mineral, protein, fat, and carbohydrate. In this study, those who had history of diarrhea in the last two weeks were 4.43 times at risk of having chronic energy deficiency than their counter parts. This findings consistent with the study conducted in Dilla(AOR $=3.40)$ [36] but not in a study done in Butajira and Humera [20, 40].

Educational status and Chronic energy deficiency show significant association and those having no formal education increased the likely hood of developing chronic energy deficiency by about two fold $(\mathrm{AOR}=2.05)$ as compared to those having secondary education and above. Similarly, a study conducted in Nepal and Dilla revealed that Illiterate people were 2.3 and 3.5 times more likely to be chronic energy deficient as compared to people who can read and write respectively $[34,36]$. A meta-analysis done among women living with HIV in SSA also supports this finding [13]. This could be explained by when Individuals having no formal education, they might not have the knowhow of eating diversified diet and hygiene which strongly affects their nutritional status. On the other hand, individuals having no formal education will have low employment opportunity which will affect their level of income and food consumption [44].

The limitation of the study was the study design which is cross-sectional; we cannot able to establish a cause and effect relationship. Since the questions were interviewer - administered there will be some social desirability bias in answering the dietary diversity and wealth index questions. The data collection period was during the fasting period, it affected the dietary diversity score of the participants since animal products excluded during fasting period. 
Table 4 Factors Associated With chronic energy deficiency among Adults Living with HIV in Gondar university referral Hospital, NWE, Gondar, 2016

\begin{tabular}{|c|c|c|c|c|}
\hline \multirow[t]{2}{*}{ Variables } & \multicolumn{2}{|c|}{ Chronic energy deficiency } & \multirow[t]{2}{*}{ COR 95\%Cl } & \multirow[t]{2}{*}{ AOR $95 \% \mathrm{Cl}$} \\
\hline & Yes & No & & \\
\hline \multicolumn{4}{|l|}{ Sex } & \multirow[t]{3}{*}{$\mathrm{b}$} \\
\hline Male & 19 & 93 & $.87(0.68,1.59)$ & \\
\hline Female & 39 & 166 & 1.00 & \\
\hline \multicolumn{4}{|l|}{ Age } & \multirow[t]{4}{*}{ b } \\
\hline $18-29$ & 14 & 40 & $1.97(0.85,4.54)$ & \\
\hline $30-44$ & 30 & 140 & $1.20(0.60,2.41)$ & \\
\hline$\geq 45$ & 14 & 79 & 1 & \\
\hline \multicolumn{4}{|l|}{ Religion } & \multirow[t]{3}{*}{ b } \\
\hline Orthodox & 54 & 241 & 1 & \\
\hline Muslim & 4 & 18 & $0.99(0.32,3.0)$ & \\
\hline \multicolumn{4}{|l|}{ Residency } & \multirow[t]{3}{*}{ b } \\
\hline Urban & 48 & 239 & 1 & \\
\hline Rural & 10 & 20 & $2.49(1.09,5.65)^{a}$ & \\
\hline \multicolumn{4}{|l|}{ Marital status } & \multirow[t]{3}{*}{ b } \\
\hline Unmarried & 34 & 124 & $1.54(0.86,2.74)$ & \\
\hline Currently married & 24 & 135 & 1 & \\
\hline \multicolumn{5}{|l|}{ Educational status } \\
\hline No formal education & 27 & 70 & $2.57(1.29,5.13)^{a}$ & $2.05(1.01,4.21)^{c}$ \\
\hline Primary education & 15 & 82 & $1.22(0.57,2.61)$ & $0.89(0.39,2.00)$ \\
\hline Secondary and above & 16 & 107 & 1 & 1 \\
\hline \multicolumn{4}{|l|}{ Occupation } & \multirow[t]{3}{*}{ b } \\
\hline Unemployed & 14 & 76 & $0.766(0.39,1.48)$ & \\
\hline Employed & 44 & 183 & 1 & \\
\hline \multicolumn{4}{|l|}{ Wealth Index } & \multirow[t]{4}{*}{ b } \\
\hline Low & 26 & 79 & 1 & \\
\hline Medium & 14 & 92 & $0.46(0.22,0.94)$ & \\
\hline High & 18 & 88 & $0.62(0.31,1.21)$ & \\
\hline \multicolumn{4}{|l|}{ Dietary Diversity } & \multirow[t]{3}{*}{ b } \\
\hline Inadequate & 47 & 231 & 1 & \\
\hline Adequate & 11 & 28 & $1.93(0.89,4.14)$ & \\
\hline \multicolumn{4}{|l|}{ ART status } & \multirow[t]{3}{*}{ b } \\
\hline Pre-ART & 14 & 28 & $2.6(1.28,5.38)^{a}$ & \\
\hline On ART & 44 & 231 & 1 & \\
\hline \multicolumn{5}{|l|}{ Stage of the Disease } \\
\hline One & 41 & 266 & 1 & 1 \\
\hline Two & 9 & 22 & $2.25(0.97,5.24)$ & $2.02(0.83,4.91)$ \\
\hline Three and four & 8 & 11 & $4.0(1.52,10.50)^{\mathrm{a}}$ & $3.84(1.39,10.61)^{c}$ \\
\hline \multicolumn{5}{|l|}{ CD4 } \\
\hline$<200$ & 10 & 38 & $1.21(0.56,2.59)$ & \\
\hline$>200$ & 48 & 221 & 1 & \\
\hline Toilet availability & & & & $\mathrm{b}$ \\
\hline
\end{tabular}


Table 4 Factors Associated With chronic energy deficiency among Adults Living with HIV in Gondar university referral Hospital, NWE, Gondar, 2016 (Continued)

\begin{tabular}{|c|c|c|c|c|}
\hline Yes & 45 & 231 & 1 & \\
\hline No & 13 & 28 & $2.38(1.14,4.95)^{a}$ & \\
\hline \multicolumn{5}{|c|}{ Diarrhea } \\
\hline Yes & 12 & 13 & $4.93(2.12,11.49)^{a}$ & $4.43(1.83,10.72)^{c}$ \\
\hline No & 46 & 246 & 1 & 1 \\
\hline \multicolumn{5}{|c|}{ Anemia } \\
\hline Yes & 20 & 61 & 1 & \\
\hline No & 38 & 198 & $1.70(0.96,3.15)$ & \\
\hline
\end{tabular}

${ }^{a}$ variables which were significant by bivariate analysis

${ }^{b}$ variables which were not significant in multivariate analysis using back ward likelihood ratio variable selection method

cindicates variables which show significant association in multivariate analysis

\section{Conclusion}

The Prevalence of chronic energy deficiency in this study was medium. Educational status, Stage of the disease and having diarrhea in the last two weeks were the important risk factors associated with chronic energy deficiency. Health care workers better to bear in mind that in addition to giving HAART, consistent and proper nutritional assessment and early diagnosis and treatment of diarrhea should be a vital part of HIV management and a prerequisite to the planning of general nutritional care and support.

\section{Abbreviations}

AIDS: Acquired immuno deficiency syndrome; AOR: Adjusted odds ratio; ART: AntiRetro-viral treatment; AZT: Zidoviudine; BMl: Body mass index; CD4: Cluster of differentiation 4; CED: Chronic energy deficiency; Cl: Confidence interval; DDS: Dietary diversity score; EFV: Efavirenz; Gl: Gastro intestinal; GURH: Gondar University Referral Hospital; HAART: Highly active anti-retroviral treatment; HIV: Human immune virus; NNP: National nutrition program; NVP: Nevirapine; PLWH: People living with HIV; RNA: Ribonucleic acid; TDF: Tenofovir; VCT: Voluntary counseling and testing; WHO: World Health Organization

\section{Acknowledgment}

The researchers want to acknowledge in advance the Department of Health Officer staffs, Gondar University Referral Hospital management, Gondar University Referral Hospital ART clinic staffs, study participants and Data collectors.

\section{Funding}

No fund was obtained for this study.

\section{Availability of data and materials}

Data will be available up on the request of the corresponding author.

\section{Authors' contributions}

MF contributed in the generation of the topic, preparation of proposal, data collection, analyses and development of the manuscript. MM, MM, and AT contributed in reviewing the proposal, assisted in data collection, analysis and critical review of final manuscript. TA and KA contributed in critically reviewing the proposal, the manuscript and processed publication. All authors read and approved the final manuscript.

\section{Competing interests}

The authors declare that they have no competing interests.

\section{Consent for publication}

Not applicable.
Ethics approval and consent to participate

Ethical clearance was obtained from ethical review committee of University of Gondar, College of Medicine and Health Sciences(Ref.No/IPH/2883/02/ 2016), Institute of Public Health prior to data collection. Written informed consent was obtained from each study participant after the purpose of the study explained. Individuals who were not volunteer to continue from the beginning or from any part of the interview were respected to do so. Privacy, anonymity and strict confidentiality were maintained during the interview process. Nutrition education was given to all subjects.

\section{Author details}

${ }^{1}$ Department of Human Nutrition, College of Medicine and Health Sciences, University of Gondar, Gondar, Ethiopia. ${ }^{2}$ Department of Epidemiology and Biostatistics, College of Medicine and Health Sciences, University of Gondar, Gondar, Ethiopia.

Received: 5 October 2016 Accepted: 24 January 2017

Published online: 01 February 2017

\section{References}

1. WHO. Global health observatory data, HIV/AIDS. 2016.

2. Stuart G, Lawrence H, Jackson R. HIV/AIDS, Food and nutrition security: impacts and actions. 2001.

3. WHO. Regional office for Africa, Ethiopia/HIV/AIDS. 2014

4. FANTA. HIV/AIDS:A guide for nutrition, care and support. 2001.

5. Piwoz E, Preble E. HIV/AIDS and nutrition: a review of the literature and recommendations for nutritional care and support in sub-Saharan Africa. 2000.

6. Zachariah R, Fitzgerald M, Massaquoi M, Pasulani O, Arnould L, Makombe S. Risk factors for high early mortality in patients on antiretroviral treatment in a rural district of Malawi. AIDS. 2006;20(18):2355-60.

7. Sztam K, Fawzi W, Duggan C. Macronutrient supplementation and food prices in HIV treatment. J Nutr. 2010;140(1):96-9.

8. Anabwani G, Navario P. Nutrition and HIV/AIDS in sub-Saharan Africa: an overview of nutrition. Nutrition. 2005;21(1):96-9.

9. Alison T. Guide to Screening for food and nutrition services among adolescents and adults living with HIV. Food and Nutrition technical Assistance project (FANTA). 2010. http://www.fantaproject.org. Accessed June 2016.

10. Mangili A, Murman D, Zampini A, Wanke C. Nutritionand HIV infection: review of weight loss and wasting in the era of HAART. Clin Infect Dis. 2006; 42(6):836-42.

11. WHO, UNAIDS, UNICEF. GLOBAL HIV/AIDS Response Epidemic Update and Health Sector Progress towards Universal Access. Progress Report. 2011.

12. John R, Douglas C. Nutritional aspects of HIV-associated wasting in subSaharan Africa. Am J Clin Nutr. 2010;94(4):1138S-42S.

13. Olalekan AU. Prevalence and pattern of HIV-related malnutrition among women in sub-Saharan Africa: a meta-analysis of demographic health surveys. BMC Public Health. 2008:8:226.

14. Andrade C, Jesus R, Andrade T, Oliveira N, Nabity S, Ribeiro G. Prevalence and characteristics associated with malnutrition at hospitalization among patients with acquired immunodeficiency syndrome in Brazil. 2012. 
15. Bhimavarapu R, Chitra KP, Ramasway M. Nutritional Status and Serum Zinc Levels in HIV infected individuals compared to control subjects Undergoing Anti Retro Viral Therapy(ART). J Pharm Sci Res. 2010;2(11):745-51.

16. Folasire O, Folasire A, Sanusi R. Measures of nutritional status and quality of life in adult people living with HIV/AIDS at a Tertiary Hospital in Nigeria. Food Nutr Sci. 2015;6(4):412.

17. Ritte S, Kessy A. Social factors and lifestyle attributes associated with nutritional status of people living with HIV/AIDS attending care and treatment clinics in Ilala district, Dar es Salaam. East African journal of public health. 2014;9(1):33-8.

18. Nnyepi M. The risk of developing malnutrition in people living with HIV/ AIDS: Observations from six support groups in Botswana. South Afr J Clin Nutr. 2009;22(2).

19. Fufa H, Umeta M, Taffesse S, Mokhtar N, Aguenaou H. Nutritional and immunological status and their associations among HIV-infected adults in Addis Ababa. Ethiopia. 2009;30(3):227-32. Pubmed.

20. Gedle D, Gelaw B, Muluye D, Mesele M. Prevalence of malnutrition and Its associated factors among adult people living with HIV/AIDS receiving anti-retroviral therapy at Butajira Hospital, Southern Ethiopia. BMC Nutrition. 2015;1(1):5.

21. Anbesaw M, Tadesse A, Mekonen A, Amare T. Undernutrition and associated factorsamong adults living with human immune deficiency virus in dembia district, northwest Ethiopia. Archives of Public Health. 74(1):33.

22. $\mathrm{MOH}, \mathrm{FDRE}$. National Guidelines for HIV/AIDS and Nutrition. 2008.

23. Getu D, Fassil T. Biostatistics lecture note for health science students. 2005.

24. CSA. Ethiopian demographic and health survey. 2011.

25. Rutstein S, Johnson K. The DHS wealth index. DHS comparative reports. 2004.

26. Ginna K, Terri B, Marie C. Guidelines formeasuring household and individual dietary diversity. 2013.

27. Rockville. National Health and Nutrition Examination Survey III, 1988-1994 (ICPSR 2231). http://www.icpsr.umich.edu/icpsrweb/NACDA/studies/2231\#. Accessed July 2016.

28. BIOBANK U. Height measurement manual. 2011.

29. WHO. Global Database on Body Mass Index. World Health Organization. 2012.

30. WHO, CDC. World wide prevalence of Anemia. 1993-2005.

31. Daniel M, Mazengia F, Birhanu D. Nutritional status and associated factors among adult HIV/AIDS clients in Felege Hiwot Referral Hospital, Bahir Dar, Ethiopia. Sci J Public Health. 2013;1(1):24-31

32. Garcia-Prats AJ, McMeans AR, Ferry GD, Klish WJ. Nutrition and HIV/AIDS www.bipai.org/Curriculums/HIV-Curriculum/Nutrition-and-HIV/AIDS.aspx. Accessed May 2016.

33. WHO. Nutrition Landscape Information System (NLIS). Country Profile Indicators Interpretation Guide. 2010.

34. Thapa R, Amatya A, Pahari D, Bam K, Newman M. Nutritional status and its association with quality of life among people living with HIV attending public anti-retroviral therapy sites of Kathmandu Valley, Nepal. AIDS Res Ther. 2015;12(1):14

35. Paton N, Sangeetha S, Earnest A, Bellamy R. The impact of malnutrition on survival and the CD4 count response in HIV-infected patients starting antiretroviral therapy. HIV Medicine. 2006;7(5):323-30.

36. Hailemariam S, Bune G, Ayele H. Malnutrition: prevalence and its associated factors in People living with HIV/AIDS, in Dilla University Referral Hospital. Arch Public Health. 2013;71(1):13

37. Khalili H, Soudbakhsh A, Hajiabdolbaghi M, Dashti-Khavidaki S, Poorzare A, Saeedi A. Nutritional status and serum zinc and selenium levels in Iranian HIV infected individuals. BMC Infect Dis. 2008;8(1):165.

38. Hu W, Jiang $H$, Chen W, Deng B, Wang W. Malnutrition in hospitalized people living with HIV/AIDS: evidence from a cross-sectional study from Chengdu, China. Asia Pac J Clin Nutr. 2011;20(4):544.

39. Wasie B, Kebede Y, Yibrie A. Nutritional status of adults living with HIV/AIDS at the University of Gondar Referral Hospital, Northwest Ethiopia. Ethiop J Health Biomed Sci. 2014;3(1).

40. Hadgu T, Worku W, Tetemke D, Berhe H. Undernutrition among HIV positive women in Humera hospital, Tigray, Ethiopia, 2013. BMC Public Health. 2013; 13(1):943.

41. Mekuria A, Habtamu J. Malnutrition and associated factors among adult individuals receiving highly active antiretroviral therapy in health facilities of Hosanna Town, Southern Ethiopia. Open Access Library Journal. 2015;2.

42. Crush J, Frayne B, Grant M. The regional network on HIV/AIDS, livelihoods and food security. 2006.
43. Patwari AK. Diarrhoea and malnutrition interaction. 1999. Pubmed.

44. Benta AA, James C, Elizabeth K. Effect of mother's education on child's nutritional status in the slums of Nairobi. 2012.

\section{Submit your next manuscript to BioMed Central and we will help you at every step:}

- We accept pre-submission inquiries

- Our selector tool helps you to find the most relevant journal

- We provide round the clock customer support

- Convenient online submission

- Thorough peer review

- Inclusion in PubMed and all major indexing services

- Maximum visibility for your research

Submit your manuscript at www.biomedcentral.com/submit
C Biomed Central 